\title{
Expression and variation of serum cytokines in mouse model with different types of bacteremia
}

\author{
Zhenhui WANG ${ }^{1}$, Zhengjiang JIN ${ }^{1 *}$
}

\begin{abstract}
To investigate the expression and variation of MIP-1 $\beta$, MIP-2, IL-12p40 and IL-12p70 in mice with bloodstream infection caused by four types of bacteria. ICR mouse models of bloodstream infection with Staphylococcus aureus (Sa), Enterococcus faecalis (Ef), Escherichia coli (Ec) and Klebsiella pneumonia (Kp) were established. Mice were infected by bacteria for $0.5 \mathrm{~h}$, $1 \mathrm{~h}, 3 \mathrm{~h}, 6 \mathrm{~h}, 12 \mathrm{~h}, 24 \mathrm{~h}$ and $48 \mathrm{~h}$, while mice in control group was injected with PBS. MIP-1 $\beta$, MIP-2, IL-12p40 and IL-12p70 in serum were detected by Luminex xMAP assay and were compared among different groups at different time points. MIP- $1 \beta$ increased significantly after bacteria were injected for each time point $(\mathrm{p}<0.05)$. MIP-1 $\beta$ and MIP-2 in Ec and Kp groups were significantly higher than those in Sa and Ef groups $(\mathrm{p}<0.01)$. IL-12p40 peaked at $3 \mathrm{~h}$ after injection and remained at high level for $12 \mathrm{~h}$ in four groups. IL-12p70 in Sa group increased significantly and reached the maximum value $6 \mathrm{~h}$ after infection, while in the other three groups, it increased significantly $3 \mathrm{~h}$ after infection $(\mathrm{P}<0.05)$.
\end{abstract}

Keywords: bacteremia; cytokine; chemokine.

Practical Application: The combination of multiple cytokines or chemokine can provide laboratory data for treatment at early stage of infection.

\section{Introduction}

Bloodstream infection or bacteremia refers to the persistence of pathogens invading the blood circulation, which rapidly spreads and causes systemic symptoms such as chill, fever, skin rash and hepatosplenomegaly (Mwaigwisya et al., 2015). Its pathogens mainly include bacteria and fungi and the prognosis is poor (Nieman et al., 2016; Kothari et al., 2014; Altuntas \& Korukluoglu, 2019; Silva et al., 2020; Figueroa-González et al., 2019). In recent years, due to the abuse of antibiotics, the increased application of various invasive diagnostic techniques such as intravascular catheters, the incidence of bacteremia has been increasing during the past several decades, with a mortality rate of up to 30\% (Ozsurekci et al., 2016; Conn et al., 2017). Therefore, early diagnosis and treatment of bacteremia is particularly critical. Currently, blood culture is considered as the gold standard for diagnosing bacteremia (Singh et al., 2018). However, it takes three to five days to generate positive results and the positive rate is quite low. Thus, patients with bacteremia cannot get timely and accurate diagnosis and treatment. In addition, molecular diagnostic tools such as real-time PCR (PCR), Sanger sequencing, peptide nucleic acid + fluorescence in situ hybridization (PNA + FISH) have been studied and applied in clinical laboratories (Sabat et al., 2017; Rabensteiner et al., 2015). However, the procedures of these methods are complicated time-consuming, which makes them difficult to provide early diagnosis for bacteremia.

Bacteremia induces the production of a series of peptides released by body's immune cells, such as cytokines, chemokines and acute phase-reactive proteins including macrophage inflammatory protein-1 $\beta$ (MIP-1 $\beta$ ), macrophages inflammatory protein-2 (MIP-2), interleukin (IL)-12p70, C-reactive protein (CRP) and procalcitonin (PCT) (Duan et al., 2016). CRP and PCT have now been widely used in the clinical laboratories, but their concentration rises later than other cytokines10. In addition, both these two markers have poor specificity for diagnosis of bacteremia and cannot distinguish between Gram-negative and Gram-positive infections (Sun et al., 2017; Hamada Imam \& Gamal, 2016). Both MIP-1 $\beta$ and MIP-2 belong to the chemokines, which can guide mononuclear cells to inflammatory site and then induces the infiltration of inflammatory cells and exerts anti-inflammatory effects when the organism is infected by bacteria (Zhang et al., 2015). The IL-12 family is a cytokine family consisting of heterodimeric IL-12, IL-23, IL-27, IL-35, IL-12p40 monomer and IL-12 p40 homodimerIL-12p70 is mainly produced by dendritic cells, mononuclear macrophages and other antigen-presenting cells and can promote the proliferation and differentiation of CD4+ T helper cells (Th1), thus playing an important role in immunity after bacterial infection (Jacobson et al., 2016).

Changes and differences of MIP-1 $\beta$, MIP-2, IL-12p40 and IL-12p70 in the immune process after infection of different types of bacteria have rarely been reported. In addition, our research group has established the bloodstream infection mouse model with single bacteria. Therefore, in our current study, our study aims to investigate the changes of MIP-1 $\beta$, MIP-2, IL-12p40 and IL-12p70 in the early stage of different bacterial infections and to evaluate their efficiency in distinguishing between Gram-positive 
and Gram-negative infections, thus providing solid clinical data for differential diagnosis at the early stage bloodstream infection. We used this mouse model and simultaneously detected the serum concentrations of MIP1 $\beta$, MIP-2 and IL-12p70 using Luminex xMAP assay. Concentrations of these chemokines in the serum of Staphylococcus aureus group, Enterococcus faecalis group, Escherichia coli group and Klebsiella pneumonia group at different time points were detected and compared with PBS control group.

\section{Materials and methods}

\subsection{Research subjects and bacteria strains.}

SPF grade CD-1 (ICR) male mice were purchased from Liantonglihua Experimental Animal Science and Technology Co., Ltd., weighing $25 \sim 27 \mathrm{~g}$. The mice were kept at the temperature of 18 to $25^{\circ} \mathrm{C}$ and humidity of $50 \%$ to $70 \%$. The animals were acclimated to the environment for 1 week before experiment.

Standard strain of Staphylococcus aureus (ATCC 25923), Escherichia coli (ATCC 25922), Enterococcus faecalis (ATCC 29212) and Klebsiella pneumonia (ATCC 700603) were purchased from Solarbio (Beijing, China).

\subsection{Equipment and reagents}

Main instrument and reagent included full temperature oscillator (Taicang Experimental Equipment Factory), McNeill turbidity meter (French BioMerieux), centrifuge (Thermo Fisher, USA), Lumine xMAP system and its supporting reagents (Merck, Germany).

\subsection{Establishment of mouse model with bacteremia}

175 mice were randomly divided into Staphylococcus aureus (Sa) group, Enterococcus faecalis (Ef) group, Escherichia coli (Ec) group, Klebsiella pneumoniae (Kp) group and sterile PBS control group. Each type of bacteria group was further divided into 7 sub-groups according to the time of specimen collection (5 mice per sub-group). The median lethal doses (LD50) of Staphylococcus aureus, Enterococcus faecalis, Escherichia coli and Klebsiella pneumonia were first explored. In each experimental group, the bacteria were injected into the mice at the corresponding half LD50 concentration through the tail vein at the dose of $0.01 \mathrm{~mL} / \mathrm{g}$. The control group was injected with the same dose of sterile PBS in the tail vein. The mice were sacrificed at $0.5 \mathrm{~h}, 1 \mathrm{~h}, 3 \mathrm{~h}, 6 \mathrm{~h}, 12 \mathrm{~h}, 24 \mathrm{~h}$ and $48 \mathrm{~h}$ after infection, and blood was collected for further detection.

\subsection{Collection and storage of blood samples.}

Blood was collected from eyeballs of the mice and placed in EP tubes with EDTA as anticoagulation. After centrifugation at $5000 \mathrm{r} / \mathrm{min}$ for $20 \mathrm{~min}$, serum was dispensed and stored at $-80^{\circ} \mathrm{C}$ for examination.

\subsection{Detection of MIP1 $\beta, M I P-2, I L-12 p 40$ and IL-12p70}

The serum was thawed at room temperature and was centrifuged (3 $000 \mathrm{r} / \mathrm{min} 2 \mathrm{~min}$ ) before detection. The concentrations of MIP1 $\beta$, MIP-2, IL-12p40 and IL-12p70 in the serum of bacterial bloodstream infection mice models at different time points after infection of bacteria were simultaneously detected by $\mathrm{xMAP}^{\mathrm{m} w}$ technology. The $\mathrm{xMAP}^{\mathrm{m}}$ technology (Luminex) combines the principle of a sandwich immunoassay with the fluorescent-bead-based technology allowing individual and multiplex analysis of up to 100 different analytes in a single microtiter well. The $\mathrm{xMAP}^{\mathrm{m} w}$ serum assays were performed with a 96-well microplate format according to the instructions.

\subsection{Statistical analysis}

All statistical analysis was performed with SPSS 17.0 software. The normal distribution data were compared by the group $t$ test, and the comparison between the groups was analyzed by ANOVA. $\mathrm{P}<0.05$ is considered as statistically significant difference.

\section{Results}

\subsection{Determination of LD50 for each type of bacteria for mouse model establishment}

After preliminary experiments in the early stage, the median lethal doses (LD50) of Staphylococcus aureus, Enterococcus faecalis, Escherichia coli and Klebsiella pneumonia were 8. $1 \times 108 / \mathrm{m} \mathrm{L}, 9.6 \times 108 / \mathrm{m} \mathrm{L}, 8.1 \times 108 / \mathrm{mL}$ and $1.1 \times 109 / \mathrm{mL}$, respectively.

\subsection{Changes of MIP-1 $\beta$ in bloodstream infection mice model}

The concentration of MIP- $1 \beta$ significantly increased in each infection group $0.5 \mathrm{~h}$ after infection and gradually declined to normal level after reached the peak. This increase was statistically significant when compared with that in control group at the same time point $(\mathrm{p}<0.01)$. MIP- $1 \beta$ reached the maximum value $(1364.4 \pm 345.6 \mathrm{pg} / \mathrm{mL})$ at $6 \mathrm{~h}$ and then gradually decreased to $89.7 \pm 10.9 \mathrm{pg} / \mathrm{ml} 48 \mathrm{~h}$ after injected with Staphylococcus aureus. In Ef group $(3891.4 \pm 899.2 \mathrm{pg} / \mathrm{mL})$, Ec group $(16994.5 \pm 1892.2 \mathrm{pg} / \mathrm{mL})$ and Kp group ( $6987.3 \pm 678.6 \mathrm{pg} / \mathrm{mL})$, concentrations of MIP-1 $\beta$ reached the peak value $3 \mathrm{~h}$ after infection. However, the increase rate and amplitude in Ec group and Kp group were more significant than those in Sa and Ef group after infection (Figure 1A).

\subsection{Changes of MIP-2 in bloodstream infection mice model}

The concentration of MIP- 2 increased gradually in the first $12 \mathrm{~h}$ after infected with Staphylococcus aureus and Enterococcus faecalis. The peak values of MIP-2 for these two groups at $12 \mathrm{~h}$ were $(258.8 \pm 34.7 \mathrm{pg} / \mathrm{mL})$ and $(437.5 \pm 67.4 \mathrm{pg} / \mathrm{mL})$, respectively, both of which were significantly higher than those in control group $(\mathrm{P}<0.01)$. MIP-2 in Ec group $(2080.0 \pm 234.2 \mathrm{pg} / \mathrm{mL})$ and Kp group (5471.2 $\pm 1147.6 \mathrm{pg} / \mathrm{mL}$ ) reached the peak value 3 hours after infection and then gradually decreased. Both these two peak values were higher than those in Sa or Ef groups $(\mathrm{P}<0.01)$. The concentration of MIP-2 decreased to normal levels 2 days after infection in all these four groups (Figure 1B).

\subsection{Changes of IL-12p40 in bloodstream infection mice model}

The concentration of IL-12p40 in mice infected with Staphylococcus aureus was slightly higher than that in control 

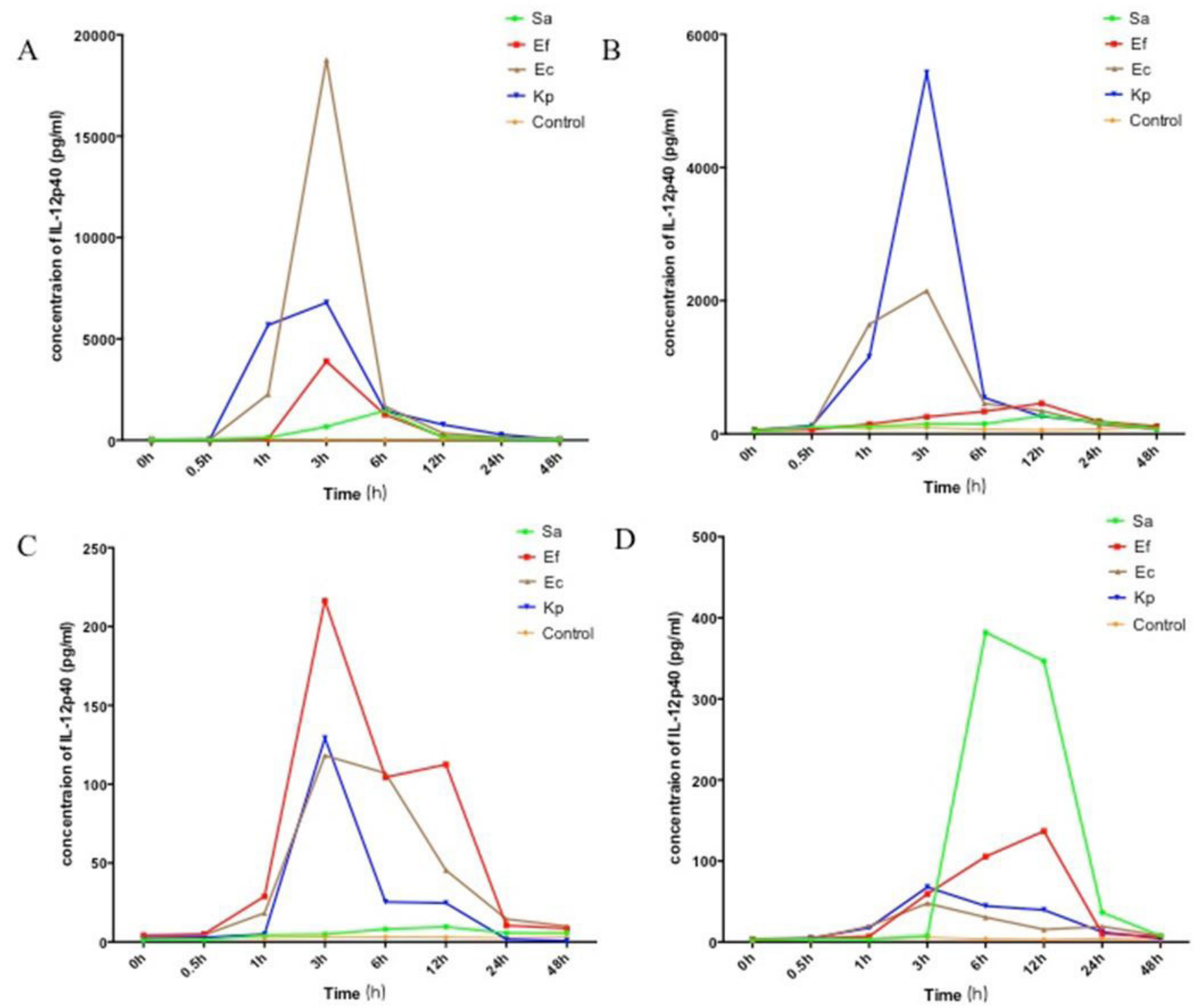

Figure 1. Changes of MIP-1 $\beta$ (A), MIP-2 (B), IL12-p40 (C) and IL12-p70 (D) at different time points in different bacteria bloodstream infection group. Sa: Staphylococcus aureus group, Ef: Enterococcus faecalis group, Ec: Escherichia coli group, Kp: Klebsiella pneumoniae group.

group after infection at each time point and this difference was not statically significant. While in Ef group, Ec group and Kp group, IL-12p40 peaked 3 hours after infection and the peak concentrations were $224.54 \pm 47.6 \mathrm{pg} / \mathrm{mL}, 132.45 \pm 10.9 \mathrm{pg} / \mathrm{mL}$ and $118.6 \pm 11.6 \mathrm{pg} / \mathrm{mL}$, respectively. After infected with these three types of bacteria for $48 \mathrm{~h}$, IL12-p40 gradually declined to normal level (Figure 1C).

\subsection{Changes of IL-12p70 in bloodstream infection mice model}

The concentration of IL-12p70 in both Sa group and Ef group significantly increased three hours after infection $(\mathrm{P}<0.05)$. It took six hours for IL-12p70 to reach the maximum value $(389.3 \pm 118.1 \mathrm{pg} / \mathrm{mL})$ in Sa group, while it took 12 hours to reach the maximum value $(127.6 \pm 10.0 \mathrm{pg} / \mathrm{mL})$ in Ef group. In both Ec and Kp groups,IL-12p70 significantly increased one hour after infection $(\mathrm{P}<0.05)$ and peaked at $3 \mathrm{~h}$ after infection, the peak concentrations were $(45.6 \pm 3.6 \mathrm{pg} / \mathrm{mL})$ and $(76.43 \pm 9.02 \mathrm{pg} / \mathrm{mL})$, respectively. Although IL-12p70 reached the peak value earlier in Ec group and Kp group (three hours after infection), the increase amplitude in Ec and Kp groups was lower than that in the other two groups (Figure 1D).

\section{Discussion}

A variety of reasons, such as the unreasonable use of antibiotics, intravascular catheters and the development of large number of invasive diagnostic techniques lead to an increase in the incidence of bloodstream infections. The diagnostic methods currently available for bloodstream infection mainly depend on blood culture. Blood culture takes 3-7 days and the positive rate is low. Thus, it cannot provide sufficient diagnosis basis at the early stage of bloodstream infection. Previous studies have indicated that cytokines and chemokine-derived serum markers after the stimulation of bacteria into the blood plays an important role in the diagnosis of bloodstream infection (Michel et al., 2017; Volta et al., 2016).

Immune response of the host differentiates among different types of bacteria. According to bacteria location in the host, 
this process can be divided into intracellular and extracellular immunity. In this study, mice were applied as experimental models. Through a large number of experiments in the early stage, four types of frequently occurred bloodstream infection models caused by Staphylococcus aureus, Enterococcus faecalis, Escherichia coli and Klebsiella pneumonia were successfully established. Then we used liquid phase chip (Luminex) to screen early biomarkers of bloodstream infection and to explore discrepancies in biomarkers among infection of different types of bacteria. Through this study, we might provide auxiliary evidence for early diagnosis of bacterial bloodstream infection and basis for subsequent clinical validation.

Both MIP- $1 \beta$ and MIP- 2 belong to the chemokines, which have a chemoattractant role and are divided into four families based on the location of cysteine residues in the ligands: CXC, CC, C, and CX3C (Schaller et al., 2017). CXC chemokines include macrophage inflammatory protein (MIP). Further biochemical separation and characterization of the protein doublet yielded two distinct, but highly related proteins, MIP- $1 \alpha$ and MIP- $1 \beta$ that shared 68\% identical amino acidsv (Allen et al., 2007). When inflammation occurs, chemokines including MIP- $1 \beta$ and MIP-2 can stimulate the accumulation of monocytes to the inflammation site, thereby exerting their anti-inflammatory effect (Azher et al., 2017). There have been many reports on MIP- $1 \alpha$, however reports concerning the changes of MIP- $1 \beta$ and MIP-2 in bacterial bloodstream infection are not that common. Thus, this study focuses on changes of MIP- $1 \beta$ and MIP-2 after different types of bacteria enter the bloodstream. Our current results indicated that MIP- $1 \beta$ and MIP-2 increased significantly in infection groups when compared with those in control group after injection at each time point. Three hours after the bacteria entered the blood, concentrations of both MIP- $1 \beta$ and MIP-2 in G- group were higher than those in G+ groups. Therefore, according to the current study, higher concentration of MIP-1 $\beta$ might be indicative of G- bacteria infection such as Escherichia coli and Klebsiella pneumoniae. Otherwise, with relative low-level increase of MIP-1 $\beta, \mathrm{G}+$ bacteria (Staphylococcus aureus, Enterococcus faecalis) tend to be the pathogens causing the bloodstream infection.

IL-12p40 plays an important role in the regulation of negative feedback mainly through competitive binding with IL-12 receptor. IL-12p40 can induce the migration of dendritic cells stimulated by macrophages and bacteria (Sugitharini et al., 2009). IL12 was generally thought to play a vital role in the early immune modulation and Th1-mediated responses and was required for polarization of naïve Thelper cells to the Th1 phenotype. Studies concerning IL-12p40 and IL-12p70 expression in Hodgkin's lymphoma 9 have been reported. In addition, p40 subunit of IL-12 was found to be induced by bacterial infection and plays an important role in host defense (Nakano et al., 2007).. In this study, the increase of IL-12p40 is quite slight after infected with Staphylococcus aureus. In Ef group, Ec group and Kp group, IL-12p40 increased significantly and reached the peak value at $3 \mathrm{~h}$ after infection. This increase suggests that surge of IL12p-40 occurs after the bacteria infection may show that it may be one of the factors contributing to the spread of inflammatory response and could then stimulate the release of cytokines and chemokines such as IL-12 and IL-23. The latter two cytokines then further increase the IL-12p40 level. However, different types of bacteria cause different responses of the host, which explains that changes of IL-12p40 varies in different experimental groups. Within one day after infection, IL-12p40 increased and remained at a high level, suggesting that IL-12p40 may play an important role in early diagnosis and disease monitoring during bacterial infection.

The literature reports that IL-12p70 plays a role in post-infection immunity (Cooper \& Khader, 2007). In this study, IL-12p70 in Sa group and Ef group began to rise six hours after injection and remained high during the next 24 hours. Increase of IL-12p in Ec group and Kp group (three hours after infection) were earlier than the other two groups, but the increase rate was lower. Therefore, IL-12p70 of mice increased when stimulated by the above-mentioned four types of bacteria, and greater increase might indicate Gram-positive bacterial infection such as Staphylococcus aureus and Enterococcus faecalis. Therefore, cytokine and chemokine testing not only contributes to the diagnosis of infection, but also roughly distinguishes between Gram-positive and Gram-negative bacteria.

In summary, the incidence of bloodstream infection still remains high and blood culture cannot provide an effective diagnostic foundation in the early stages of infection to guide early clinical decision-making and treatment. Cytokines and chemokines have broad application prospects in assisting and differentially diagnosing pathogenic bacteria in the early stages of bacteria bloodstream infection. However, the single-time point or single biomarker index results in limited diagnostic efficiency on bacteria bloodstream infection. In addition, the immune response generated by mice infected with each bacterial infection is different, suggesting that multiple cytokines should be combined together. Multiple time points could thus help to predict whether the bacteria bloodstream infection occurs or which type of bacteria caused the infection. According to the current results, if IL-12p70 is not elevated significantly, while MIP- $1 \beta$ and MIP- 2 significantly increased in the early stage of infection, it may suggest a Gram negative bacterial infection. If an infection symptom could be observed and IL-12p70 concentration increases significantly with the prolonged infection time, while MIP- $1 \beta$ and MIP-2 do not change significantly, it may suggest Gram positive bacterial infection. Of course, all the strains used in this study are standard strains. Thus, there might be differences in terms of cytokine profiles and concentrations between clinical isolates and standard strains of the same bacteria. Changes of more cytokines and chemokines after bloodstream infection ought to be investigated and we will further explore cytokines and chemokines in follow-up studies. Furthermore, we also collect clinical specimens for verification in order to achieve effective early diagnostic biomarkers for different types of pathogens.

\section{References}

Allen, S. J., Crown, S. E., \& Handel, T. M. (2007). Chemokine: receptor structure, interactions, and antagonism. Annual Review of Immunology, 25(1), 787-820. http://dx.doi.org/10.1146/annurev. immunol.24.021605.090529. PMid:17291188.

Altuntas, S., \& Korukluoglu, M. (2019). Growth and effect of garlic (Allium sativum) on selected beneficial bacteria. Food Science and Technology, 39(4), 897-904. http://dx.doi.org/10.1590/fst.10618. 
Azher, T. N., Yin, X. T., \& Stuart, P. M. (2017). Understanding the role of chemokines and cytokines in experimental models of herpes simplex keratitis. Journal of Immunology Research, 2017, 7261980. http://dx.doi.org/10.1155/2017/7261980. PMid:28491875.

Conn, J. R., Catchpoole, E. M., Runnegar, N., Mapp, S. J., \& Markey, K. A. (2017). Low rates of antibiotic resistance and infectious mortality in a cohort of high-risk hematology patients: A single center, retrospective analysis of blood stream infection. PLoS One, 12(5), e0178059. http://dx.doi.org/10.1371/journal.pone.0178059. PMid:28542412.

Cooper, A. M., \& Khader, S. A. (2007). IL-12p40: an inherently agonistic cytokine. Trends in Immunology, 28(1), 33-38. http:// dx.doi.org/10.1016/j.it.2006.11.002. PMid:17126601.

Duan, J., Xie, Y., Yang, J., Luo, Y., Guo, Y., \& Wang, C. (2016). Variation of circulating inflammatory mediators in staphylococcus aureus and Escherichia coli bloodstream infection. Medical Science Monitor, 22, 161-171. http://dx.doi.org/10.12659/MSM.896576. PMid:26772168.

Figueroa-González, I., Rodríguez-Serrano, G., Gómez-Ruiz, L., García-Garibay, M., \& Cruz-Guerrero, A. (2019). Prebiotic effect of commercial saccharides on probiotic bacteria isolated from commercial products. Food Science and Technology, 39(3), 747-753. http://dx.doi.org/10.1590/fst.07318.

Hamada Imam, M., \& Gamal, E. (2016). Procalcitonin level as a surrogate for catheter-related blood stream infection among hemodialysis patients. The Journal of Vascular Access, 18(6), 498-502. http:// dx.doi.org/110.5301/jva.5000765. PMID: 28777420.

Jacobson, J. M., Zheng, L., Wilson, C. C., Tebas, P., Matining, R. M., Egan, M. A., Eldridge, J., Landay, A. L., Clifford, D. B., Luetkemeyer, A. F., Tiu, J., Martinez, A. L., Janik, J., Spitz, T. A., Hural, J., McElrath, J., \& Frahm, N., \& ACTG A5281 Protocol Team. (2016). The Safety and Immunogenicity of an Interleukin-12-Enhanced Multiantigen DNA Vaccine Delivered by Electroporation for the Treatment of HIV-1 Infection. JAIDS Journal of Acquired Immune Deficiency Syndromes, 71(2), 163-171. http://dx.doi.org/10.1097/QAI.0000000000000830. PMid:26761518.

Kothari, A., Morgan, M., \& Haake, D. A. (2014). Emerging technologies for rapid identification of bloodstream pathogens. Clinical Infectious Diseases, 59(2), 272-278. http://dx.doi.org/10.1093/cid/ciu292. PMid:24771332.

Michel, C. S., Teschner, D., Wagner, E. M., Theobald, M., \& Radsak, M. P. (2017). Diagnostic value of sTREM-1, IL-8, PCT, and CRP in febrile neutropenia after autologous stem cell transplantation. Annals of Hematology, 96(12), 2095-2101. http://dx.doi.org/10.1007/ s00277-017-3128-1. PMid:28920169.

Mwaigwisya, S., Assiri, R. A., \& O’Grady, J. (2015). Emerging commercial molecular tests for the diagnosis of bloodstream infection. Expert Review of Molecular Diagnostics, 15(5), 681-692. http://dx.doi.org/ 10.1586/14737159.2015.1029459. PMid:25866124.

Nakano, N., Nishiyama, C., Kanada, S., Niwa, Y., Shimokawa, N., Ushio, H., Nishiyama, M., Okumura, K., \& Ogawa, H. (2007). Involvement of mast cells in IL-12/23 p40 production is essential for survival from polymicrobial infections. Blood, 109(11), 4846-4855. http://dx.doi. org/10.1182/blood-2006-09-045641. PMid:17289816.
Nieman, A. E., Savelkoul, P. H. M., Beishuizen, A., Henrich, B., Lamik, B., \& MacKenzie, C. R. (2016). A prospective multicenter evaluation of direct molecular detection of blood stream infection from a clinical perspective. BMC Infectious Diseases, 16, 314. http://dx.doi. org/10.1586/10.1186/s12879-016-1646-4.

Ozsurekci, Y., Oktay Arikan, K., Bayhan, C., Karadag-Oncel, E., Emre Aycan, A., Gurbuz, V., Hasçelik, G., \& Ceyhan, M. (2016). Can procalcitonin be a diagnostic marker for catheter-related blood stream infection in children? Jornal de Pediatria, 92(4), 414-420. http://dx.doi.org/10.1016/j.jped.2015.11.004. PMid:27131015.

Rabensteiner, J., Theiler, G., Duettmann, W., Zollner-Schwetz, I., Hoenigl, M., Valentin, T., Leitner, E., Luxner, J., Grisold, A., Valentin, A., Neumeister, P., \& Krause, R. (2015). Detection of central venous catheter-related bloodstream infections in haematooncological patients. European Journal of Clinical Investigation, 45(8), 824-832. http://dx.doi.org/10.1111/eci.12477. PMid:26058473.

Sabat, A. J., van Zanten, E., Akkerboom, V., Wisselink, G., van Slochteren, K., de Boer, R. F., Hendrix, R., Friedrich, A. W., Rossen, J. W. A., \& KooistraSmid, A. M. D. M. (2017). Targeted next-generation sequencing of the 16S-23S rRNA region for culture-independent bacterial identification increased discrimination of closely related species. Scientific Reports, 7(1), 3434. http://dx.doi.org/10.1038/s41598-017-03458-6. PMid:28611406.

Schaller, T. H., Batich, K. A., Suryadevara, C. M., Desai, R., \& Sampson, J. H. (2017). Chemokines as adjuvants for immunotherapy: implications for immune activation with CCL3. Expert Review of Clinical Immunology, 13(11), 1049-1060. http://dx.doi.org/10.108 0/1744666X.2017.1384313. PMid:28965431.

Silva, E. O. O., Nespolo, C. R., Sehn, C. P., Pinheiro, F. C., \& Stefani, L. M. (2020). Lactic acid bacteria with antimicrobial, proteolytic and lipolytic activities isolated from ovine dairy products. Food Sci. Technol., 40(Suppl. 1), 293-299. http://dx.doi.org/10.1590/fst.11019.

Singh, L., Das, S., Bhat, V. B., \& Plakkal, N. (2018). Early neurodevelopmental outcome of very low birthweight neonates with culture-positive blood stream infection: a prospective cohort study. Cureus, 10(10), e3492. http://dx.doi.org/10.7759/cureus.3492. PMid:30648034.

Sugitharini, V., Prema, A., \& Thangam, E. B. (2009). Inflammatory mediators of systemic inflammation in neonatal sepsis. Inflammation Research, 62, 1025-1034.

Sun, Y., Jiang, L., \& Shao, X. (2017). Predictive value of procalcitonin for diagnosis of infections in patients with chronic kidney disease: a comparison with traditional inflammatory markers C-reactive protein, white blood cell count, and neutrophil percentage. International Urology and Nephrology, 49(12), 2205-2216. http:// dx.doi.org/10.1007/s11255-017-1710-z. PMid:28956241.

Volta, B. J., Bustos, P. L., Cardoni, R. L., De Rissio, A. M., Laucella, S. A., \& Bua, J. (2016). Serum cytokines as biomarkers of early Trypanosoma cruzi infection by congenital exposure. Journal of Immunology (Baltimore, Md.: 1950), 196(11), 4596-4602. http:// dx.doi.org/10.4049/jimmunol.1502504. PMid:27183607.

Zhang, S., Zhao, Y., Yan, H., Wu, H., Wei, L., Zhang, Y., \& Chen, X. (2015). Pretreatment serum macrophage inflammatory protein (MIP)-1 levels predict sustained virological responses to re-treatment in patients with chronic hepatitis $\mathrm{C}$ virus infection. International Journal of Infectious Diseases, 33, 15-21. http://dx.doi.org/10.1016/j. ijid.2014.08.021. PMid:25461236. 